\title{
TRENDS IN CHEMICAL ECOLOGY REVEALED WITH A PERSONAL COMPUTER PROGRAM FOR SEARCHING DATA BASES OF SCIENTIFIC REFERENCES AND ABSTRACTS
}

\author{
JOHN A. BYERS \\ Pheromone Research Group \\ Department of Ecology, Animal Ecology \\ Lund University \\ S-223 62 Land, Sweden
}

(Received December 4, 1991; accepted April 15, 1992)

\begin{abstract}
A compiled program, JCE-REFS.EXE (coded in the QuickBASIC language), for use on IBM-compatible personal computers is described. The program converts a DOS text file of current B-I-T-S (BIOSIS Information Transfer System) or BIOSIS Previews references into a DOS file of citations, including abstracts, in a general style used by scientific journals. The latter file can be imported directly into a word processor or the program can convert the file into a random access data base of the references. The program can search the data base for up to 40 text strings with Boolean logic. Selected references in the data base can be exported as a DOS text file of citations. Using the search facility, articles in the Journal of Chemical Ecology from 1975 to 1991 were searched for certain key words in regard to semiochemicals, taxa, methods, chemical classes, and biological terms to determine trends in usage over the period. Positive trends were statistically significant in the use of the words: semiochemical, allomone, allelochemic, deterrent, repellent, plants, angiosperms, dicots, wind tunnel, olfactometer, electrophysiology, mass spectrometry, ketone, evolution, physiology, herbivore, defense, and receptor. Significant negative trends were found for: pheromone, vertebrates, mammals, Coleoptera, Scolytidae, Dendroctonus, lactone, isomer, and calling.
\end{abstract}

Key Words-BIOSIS Previews, key word search algorithm, data base, reference manager, word processing, personal computer software, semiochemical, pheromone 


\section{INTRODUCTION}

The field of chemical ecology is interdisciplinary since chemistry, including analytical methods of separation and chemical identification as well as organic synthesis, is merged with ecology, including areas of behavior, physiology, genetics, and evolution. This diverse subject area becomes even more complex as studies of animals, plants, and microorganisms are reported. The number of articles published in the field of chemical ecology has continued to expand yearly, and it becomes increasingly difficult for the scientist to assimilate these results. However, the personal computer can be used to store, manipulate, and retrieve knowledge from data bases to aid in managing this ever expanding base of knowledge. Commercial services such as B-I-T-S (BIOSIS Information Transfer System) can provide the latest references on computer disk for viewing by personal computers. BIOSIS Previews also can often be used at a university library for retrospective searches on a particular topic. The located references from such a search of the many bioscience journals and publications, from the present back to 1969 , can be downloaded to disk for a fee.

I have developed a compiled BASIC program, JCE-REFS.EXE, which runs on IBM-compatible computers from the DOS command line. The program can take DOS text files of either current monthly B-I-T-S listings or of retrospective searches of BIOSIS Previews and make a data base. This data base can then be searched for text strings (key words) and the located references/abstracts marked for export to a word processor in a format resembling a standard scientific citation. Other commercial data bases can be imported, such as MEDLINE (National Library of Medicine) and CA Search (American Chemical Society), but exported citations may not be formatted entirely accurately due to differences in punctuation.

In addition to describing the program and its general use, the objective was to download the entire 2133 references (October 1991) of the Journal of Chemical Ecology (JCE) with abstracts and make a data base. The data base then was searched repeatedly for many different key word phrases for each year (1975-1991) in order to illustrate certain trends in chemical ecology. The general areas covered were use of terms describing: (1) semiochemicals, (2) taxonomic groups, (3) methods, (4) chemical classes, and (5) general or specific subjects used in chemical ecology.

\section{METHODS AND MATERIALS}

An IBM-DOS text file from BIOSIS Previews (retrospective search) or B-I-T-S (monthly update) is required for processing by the program. Files from retrospective searches can be downloaded from a number of commercial com- 
puter data bases such as Data-Star, ESA-IRS, DIALOG, and STN. References in a BIOSIS Previews text file may contain the subject identification codes (field tags) of AN (accession number), AU (author), TI (title), SO (source), IN (author affiliation), KW (key words), BC (biosystematic codes), and ST (supertaxa). Other field codes may include CD (coden), LG (language), YR (year), CC (concept codes), and AB (abstract). Monthly updates of recently published articles are formatted slightly differently by BIOSIS, such that the AN field code is replaced with an ID (identification) code and the CS (corporate source, author address) may substitute for the IN code above. The program can be adapted to use different field codes in BIOSIS files, as well as codes in other data bases (as will be explained subsequently).

The program JCE-REFS.BAS was developed with the QuickBASIC programming language (version 4.5, Microsoft). The source code was compiled to JCE-REFS.EXE, a binary, machine-coded, executable file, by the Microsoft compiler version 4.50 and overlay linker version 3.69. IBM-compatible personal computers can execute the program in monochrome or color using characterbased monitors and DOS 2.1 or higher.

The major facilities and operation of JCE-REFS.EXE are diagrammed in Figure 1. The arrows between boxes indicate relationships between program

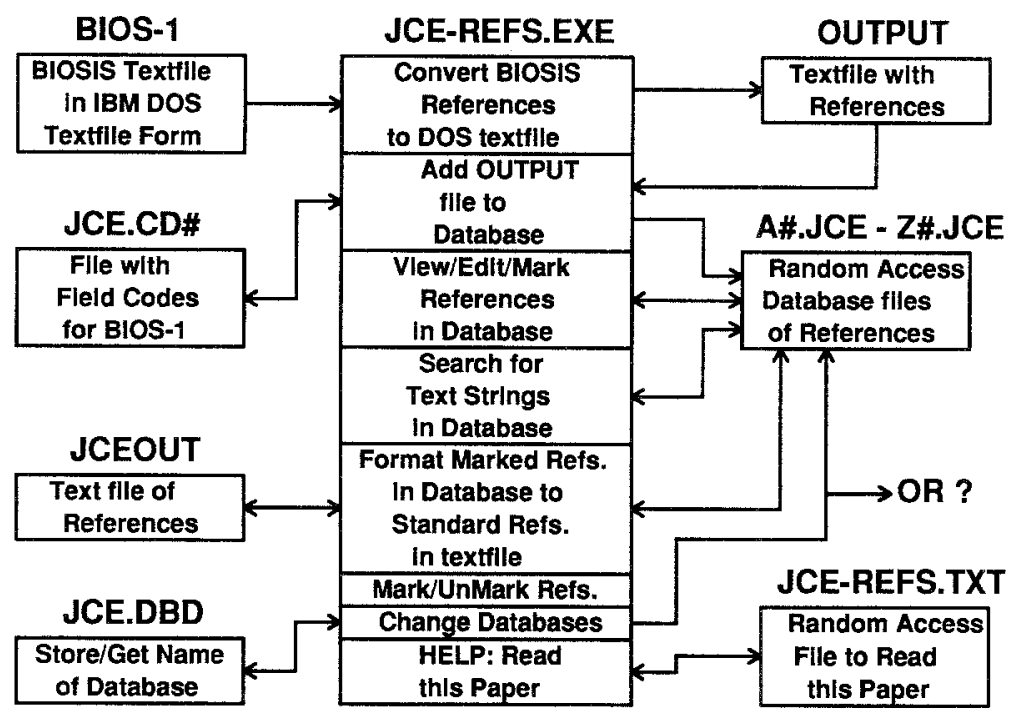

FIG. 1. Relationships of program parts of JCE-REFS.EXE, a BIOSIS file conversion and data-base searching utility for scientific reference management on the IBM-compatible personal computer. 
parts but do not necessarily denote program flow. JCE-REFS.EXE is used by typing jee-refs at the DOS command line. The program loads and checks to see if a name of a data base is in the file JCE.DBD. If no name is present, then the default extension name (\#.JCE) is placed in the file. The menu has seven options to choose from (Figure 1) besides a help section, DOS shell (DOS commands), or exiting from the program.

The first option is to convert BIOSIS files to a standard scientific reference format in a DOS textfile, always given the name OUTPUT. This is done by entering the name of the BIOSIS Previews file (e.g., named BIOS-1 and rep-

(A)

AN 850886368800 .

AU BYERS-J-A.

TI NOVEL DIFFUSION-DILUTION METHOD FOR RELEASE OF SEMIOCHEMICALS TESTING PHEROMONE COMPONENT RATIOS ON WESTERN PINE BEETLE.

SO J-CHEM-ECOL 14 (1). 1988. 199-212.

IN DEP ANIMAL ECOL, UNIV LUND, S-223 62 LUND, SWED.

$\angle G$ EN"

YR 88 .

KW DENDROCTONUS-BREVICONIS TEMNOCHILA-CHLORODIA PREDATOR MYRCENE EXOBREVICONIN PESTS.

BC 75304 Coleoptera.

ST ANIMALS\#, INVERTEBRATES\#, ARTHROPODS\#, INSECTS\#.

$A B$ Each of the pheromone components of the Western pine beetle, Dendroctonus brevicomis LeC. (Coleoptera: Scolytidae), exo-brevicomin (E) and frontalin $(F)$, were released in the forest at various ratios etc...

(B)

Byers, J.A. 1988. novel diffusion-dilution method for release of

semiochemicals testing pheromone component ratios on western pine beetle. $J$.

Chen. Ecol. 14 (1) . 199-212. $==$ dendroctonus-brevicomis temnoch $i$ la-ch lorodia predator myrcene exobrevicomin pests. 75304 coleoptera. animals\#, invertebrates\#, arthropods\#, insects\#. ab each of the pheromone components of the western pine beetle, dendroctonus brevicomis lec. (coleoptera: scolytidae). exo-brevicomin (e) and frontalin (f), were released in the forest at various ratios etc...

dep animal ecol, univ lund, $5-22362$ lund, swed

(c)

Byers, J.A. 1988. novel diffusion-dilution method for release of semiochemicals testing pheromone component ratios on western pine beetle. J. Chem. Ecol. 14 (1) - 199-212. =dendroctonus-brevicomis temnochila-chlorodia predator murcene exobre vicomin pests. 75304 coleoptera. animals\#, invertebrates\#, arthropods\#, insects\# . ab each of the pheromone components of the western pine beetle, dendroctonus $b$ reviconis lec. (coleoptera: scolytidae), exo-brevicomin (e) and frontalin (f), w ere released in the forest at various ratios etc...

dep animal ecol, univ lund, s-223 62 lund, swed

FIG. 2. The JCE-REFS.EXE program processes a BIOSIS text file (A) into a DOS text file (OUTPUT) as shown in (B), which is imported into the random access database file (B\#.JCE) as in (C) that can be searched. The reference in the data base also can be exported as a DOS text file (B) or Pro-Cite style (not shown) for use with MacIntosh and IBM-compatible personal computers. 
resented in Figure 2A). The user may look at the BIOS-1 file to see if the formatting is such that all text is indented three spaces except for the field codes. Rarely, the file can be received from BIOSIS in a corrupted condition; in this case a reformatting facility is selected to correct the file. Otherwise the user continues and is presented with a list of files (ending in .CD\#) that contain various field codes appropriate to the commercial data base. The user enters one of the names or a new name, and the field codes are loaded and presented on a menu for editing. The field codes can be used without editing or new codes added for the respective authors, title, journal, and so forth. These codes make it possible to accommodate any of several types of BIOSIS formats as well as other data base styles such as CA Search and MEDLINE. The program then reformats the BIOSIS file (BIOS-1) using the field codes. The first letters of authors are capitalized and appropriate punctuation is added. The date $(1900 \mathrm{~s}$ or 2000s) is extracted from the journal string. The title and journal letters are uncapitalized and then the first letter of each word in the journal is capitalized. This saves time in the word processor as most letters need to be lowercase in a standard citation. The abstract text is also uncapitalized so that all text searches can be in lowercase. The resulting sequential file, OUTPUT (Figure 2B), is overwritten each time, so one must process the contents, as described subsequently, before another BIOSIS file is reformatted.

After reformatting the BIOSIS file, the second option is used in which the OUTPUT file is entered as the source of references for alphabetical placement in the 26 data base files (e.g., A\#.JCE to Z\#.JCE). Each reference is formed into a long text string of 36 lines by 80 characters, so the abstract can be included (Figure $2 \mathrm{C}$ ). These 26 files are random access in which references from additional BIOSIS Previews files can be added by running options one and two again. Alternatively, another name can be chosen (option seven) in order to create additional data bases (e.g., for another journal).

The third option "View/Edit/Mark References in Data Base" allows one to scroll through the data base and view the references. Any references that are desired for word processing can be exported as a citation in the file JCEOUT by marking them (pressing the Insert key). References are unmarked with the Delete key. A global unmarking of all references also can be done (in option six). Facilities for searching for a text string and viewing the located reference and highlighted string are provided while viewing the data base.

The fourth option, "Search for Text Strings in Data Base," allows complex logic searches of the data base fields for up to two sets of 20 text strings simultaneously. The searches employ Boolean logic in one of four ways. Up to 20 text strings can be searched for in either an: (1) OR or (2) $A N D$ way. These also can be combined into: (3) $A N D / O R$ or (4) $A N D+O R$ searches with a total of up to 40 text strings. For example, an $A N D+O R$ search might look for 
("pheromone" AND "Scolytidae") and ("1980." OR “1981." OR "1982.") in each reference. Note the use of the space and period in the dates in order to avoid finding page numbers.

Prior to searching for the text strings, the user is asked whether he or she wants to save this search profile for later recall. If the search profile is saved, then the next time a search is made the user may select option five to load the search profile and begin the search without the need for entering the text strings. During the search of the data base, the program displays any located references on screen and waits for keyboard input to mark (or unmark) or continue without marking until all references in the data base are searched. Options include searches of various combinations of authors, date, title, key words, abstract, and address. A search record showing the number of references found out of the total number in the data base is displayed at the end of the search (searches take only some seconds for 2133 references).

The fifth option, "Format Marked Refs. in Data Base to Standard Refs. in Text File," is used to take the author, date, title, journal, and, optionally, the key words, abstract (if present), and address strings and export them. These are saved in a DOS text file called JCEOUT (style as in Figure 2B), which is overwritten each time this option is chosen. This file can then be imported into any word-processing program (e.g., WordPerfect, WordPerfect Corp., Orem, Utah) as well as into the scientific reference manager, CardCat (Byers, 1991).

A sixth option includes either a global unmarking or global marking of all references in the data base. The "Change Data Bases" option allows for an almost unlimited number of databases, 208 available ASCII characters for file names $=\left[\Sigma_{i=1}^{8} P_{i}^{208}\right]\left[\Sigma_{i=1}^{3} P_{i}^{208}\right]=2.7 \times 10^{25}$. Each time the program is started, it gets the current data base, which is permanently stored in the file JCE.DBD until changed by the user. The user can receive help from within the program by reading the file JCE-REFS.TXT, which includes the contents of this paper with figures. This file appears to be a standard sequential DOS text file but is actually a random access file that allows scrolling the text forward and backward on the screen.

BIOSIS Previews (from Data-Star, Radio-Suisse) was searched for all articles published in the Journal of Chemical Ecology (including abstracts and addresses) from 1975 until October 1991. The resulting search file was downloaded into 16 files of about $200 \mathrm{~K}$ each to a personal computer. The files were imported into the JCE-REFS program, which made a data base of 26 files with a total of 6 megabytes. This data base was searched by year, as described below, for certain key words as shown in Figures 3-5 and Tables 1-5 below. Except for the super taxonomic designations of BIOSIS (ending in \#, as in Table 2 and Figure 4), it should be noted that the incidence of various key words found in the titles, key words, and abstracts are minimal estimates since the entire article was not searched. Furthermore, certain key words are more likely to be men- 
tioned in the abstract than others due to the nature of the words. However, key words merely mentioned in the body of the paper, and not in the title, key words, or abstract, quite often are not of primary relevance to the article.

\section{RESULTS AND DISCUSSION}

It is commonly accepted that the number of scientific publications is increasing annually, although opinion would vary as to whether the function was geometric, exponential, or linear. The actual quantities of publications available to scientists as reflected in the BIOSIS data base is also not well known. In Figure $3 \mathrm{~A}$, the trend in publication rate is increasing, and a linear function $\left(r^{2}=0.89\right)$ describes the relationship about as well as a geometric $\left(r^{2}=0.88\right)$ or exponential equation $\left(r^{2}=0.90\right)$. In 1990 more papers were published than ever before, with over 540,000 publications from more than 9000 journals available to the chemical ecologist (BIOSIS Previews). The number of papers in the Journal of Chemical Ecology (JCE) in 1990 also was highest (281). Here too a positive linear equation $\left(r^{2}=0.90\right)$ describes the trend of increasing publication rate as well as do other curvilinear functions, although an exponential curve fits the data slightly better $\left(r^{2}=0.94\right)$. However, from Figure $3 \mathrm{~B}$ it can be seen that the number of papers in $J C E$ has increased relatively faster than the publication rate in general in BIOSIS $\left(r^{2}=0.65\right.$, positive slope, $\left.P<0.001\right)$.

The number of "pheromone" papers in BIOSIS has increased linearly during the period from 1975 to $1990\left(r^{2}=0.92\right)$ at the same rate as the increase in publications in BIOSIS (same percentage, Figure 3B, slope not significantly different from 0 ). On the other hand, the rate of pheromone papers in JCE has decreased (Figure 3B, Table 1). The uses of other semiochemicals such as "'allomone," "allelochemic," and "semiochemical" have increased, although use of any combination of these in papers has not changed significantly over the period (Table 1). Uses of the words "deterrent" and "repellent" have increased (Table 1).

Most papers in JCE concern "animals" (average yearly percentage of 89.4), and "insects" make up the majority of these (79\%) while "vertebrates" involve $13.9 \%$ of all papers, and "microorganisms" only $7.4 \%$ (Table 2 ). The percentage of animal papers has remained relatively constant, as has that for insects and "Lepidoptera," while the trend in vertebrate papers has decreased (Table 2), although the vertebrate trend over the last 15 years has been stable (Figure 4). In addition to vertebrates, other taxa in Table 2 show significant negative trends: "mammals" and "Coleoptera" (including "Scolytidae" and "Dendroctonus"). Significant positive trends are shown for plants (only "vascular") and "angiosperms" and "dicots," but "gymnosperms" and "monocots" show no significant relative changes (Table 2, Figure 4). The increase in 

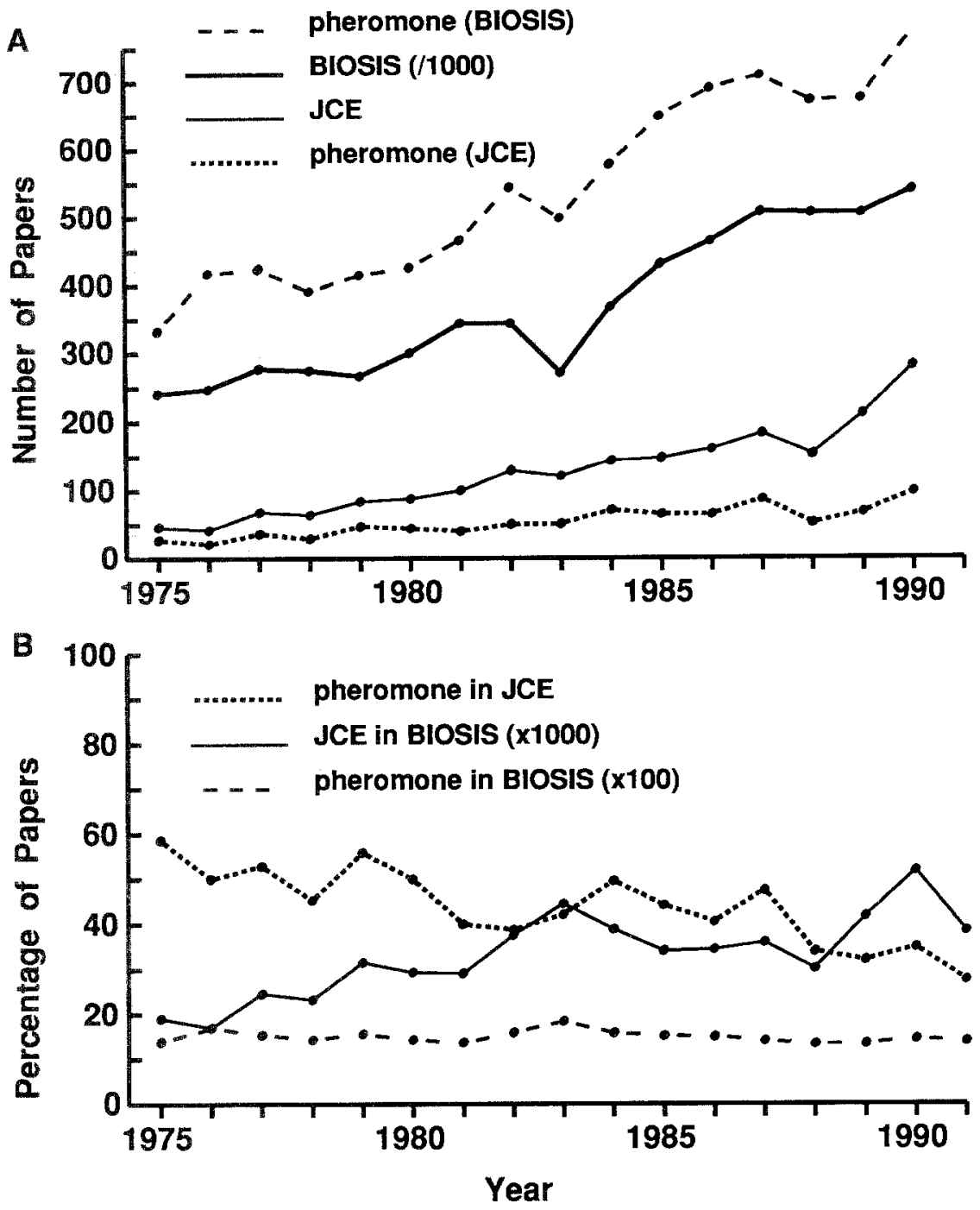

FIG. 3. (A) Number of papers with key word "pheromone" and total papers published per year in BIOSIS or Journal of Chemical Ecology (JCE), and (B) percentage of papers with "pheromone" in JCE or BIOSIS, and percentage of JCE papers in BIOSIS.

papers on plants may be real in part, but part of the increase also may be due to more often mentioning the "plant-insect" relationship than was done earlier.

There has been no significant change in the percentage of papers mentioning a "method" or "technique" useful to chemical ecology (Table 3). The use of 
Table 1. Positive and Negative Trends from 1975 to 1991 in Percentage of Papers in Journal of Chemical Ecology Using Various Semiochemicals in TITLE, Key Words, or abstract (Linear Regression with arcsin SQuare Root Transformation of Percentages) ${ }^{a}$

\begin{tabular}{lrrccc} 
Semiochemical & $N$ & Mean $\% \pm \mathrm{SD}$ & $r^{2}$ & Slope $\pm 95 \% \mathrm{CL}$ & $P$ (slope $=0$ ) \\
\hline Semiochemical & 69 & $2.27 \pm 2.79$ & 0.72 & $1.9 \pm 0.6$ & $<0.001^{*}$ \\
Pheromone & 882 & $43.79 \pm 8.68$ & 0.68 & $-1.4 \pm 0.5$ & $<0.001^{*}$ \\
Kairomone & 85 & $4.12 \pm 2.72$ & 0.07 & $-0.4 \pm 0.7$ & 0.3 \\
Allomone & 33 & $1.36 \pm 1.51$ & 0.23 & $0.7 \pm 0.7$ & $0.05^{*}$ \\
Allelochemic & 114 & $4.11 \pm 4.33$ & 0.66 & $2.1 \pm 0.8$ & $<0.001^{*}$ \\
Any of above & 1105 & $52.81 \pm 9.17$ & 0.18 & $-0.8 \pm 0.9$ & 0.09 \\
Deterrent & 72 & $3.04 \pm 2.16$ & 0.40 & $1.0 \pm 0.7$ & $0.006^{*}$ \\
Inhibitor & 148 & $6.66 \pm 2.32$ & 0.09 & $0.3 \pm 0.5$ & 0.25 \\
Repellent & 53 & $2.12 \pm 1.53$ & 0.48 & $1.0 \pm 0.6$ & $0.002^{*}$ \\
Attractant & 249 & $12.43 \pm 3.47$ & 0.13 & $-0.4 \pm 0.5$ & 0.15 \\
& & & & &
\end{tabular}

${ }^{a} P$ values with asterisks indicate slopes are significantly different from zero $(\alpha=0.05)$.

"wind tunnel" appears to have increased (although found in only $1.6 \%$ of the papers), while "bioassay" use has not changed but is used by $15.4 \%$ of JCE papers. The use of "olfactometer," "electrophysiology" (and related words), and mass spectrometry (GC-MS) have increased, while no significant trends were found for gas chromatography (including "GLC"), thin layer chromatography ("TLC"), capillary GC, high (pressure or performance) chromatography ("HPLC"), and nuclear magnetic resonance spectroscopy ("NMR," Table 3).

There were no significant trends in the frequency of use of several chemical groups (Table 4) except for lactone and isomer (negative trends) and a positive trend for ketone. Surprisingly, the use of "enantiomer" or "optical isomer" has not changed significantly over the period. Even when all chemical groups are searched for in an $O R$ way, there is no significant change in relative frequency, with about $47 \%$ of the papers mentioning one or more chemical group. Searches of various prefixes indicating carbon chain length from 11 to 19 (undec, dodec, tridec, tetradec, pentadec, hexadec, heptadec, octadec, and nonadec) substantiated the commonly held view that even-carbon chains are more frequently part of semiochemicals than are odd-carbon chains (Figure 5). The most common chain unit mentioned was 14 carbons (Figure 5) and was found in $22.3 \%$ of the Lepidoptera papers, or $86.3 \%$ of the papers with "tetradec" (e.g., tetradecenyl acetate) also included "Lepidoptera."

Chemical ecology combines the biological fields of ecology, behavior, evolution, genetics, and physiology with chemistry. There are no significant trends in the use of the words "ecology" or "behavior," probably since these 
Table 2. Positrve and Negative Trends from 1975 to 1991 in Percentage of PAPERs IN Journal of Chemical Ecology Investigating VARIous TAXa Found IN Trtle, Key Words, or Abstract (Linear Regression with Arcsin Square Root Transformation of Percentages) ${ }^{a}$

\begin{tabular}{lrclrc}
\hline \multicolumn{1}{c}{ Taxa } & $N$ & Mean $\% \pm \mathrm{SD}$ & $r^{2}$ & Slope $\pm 95 \% \mathrm{CL}$ & $P$ (slope $=0$ ) \\
\hline Microorganisms\# & 157 & $7.37 \pm 2.62$ & 0 & $-0.03 \pm 0.5$ & 0.92 \\
Plants\# & 938 & $41.61 \pm 10.54$ & 0.46 & $1.5 \pm 0.9$ & $0.003^{*}$ \\
Vascular plants\# & 859 & $38.21 \pm 9.84$ & 0.45 & $1.4 \pm 0.8$ & $0.003^{*}$ \\
Nonvascular plants\# & 102 & $4.93 \pm 1.9$ & 0 & $-0.04 \pm 0.5$ & 0.85 \\
Gymnosperms\# & 157 & $7.48 \pm 3.25$ & 0 & $0.05 \pm 0.7$ & 0.87 \\
Angiosperms\# & 691 & $30.03 \pm 9.45$ & 0.58 & $1.6 \pm 0.7$ & $<0.001^{*}$ \\
Dicot:\# & 574 & $25.27 \pm 7.91$ & 0.45 & $1.2 \pm 0.7$ & $0.003^{*}$ \\
Monocots\# & 194 & $8.58 \pm 3.78$ & 0.21 & $0.6 \pm 0.7$ & 0.06 \\
Animals\# & 1888 & $89.38 \pm 6.05$ & 0.23 & $-0.9 \pm 0.9$ & 0.054 \\
Vertebrates\# & 274 & $13.88 \pm 4.3$ & 0.27 & $-0.6 \pm 0.5$ & 0.03 \\
Mammals\# & 199 & $10.85 \pm 4.04$ & 0.51 & $-1.0 \pm 0.5$ & $0.002^{*}$ \\
Fish\# & 43 & $2.34 \pm 1.5$ & 0.06 & $-0.3 \pm 0.8$ & 0.36 \\
Invertebrates\# & 1646 & $77.19 \pm 6.68$ & 0.02 & $-0.2 \pm 0.8$ & 0.57 \\
Arthropods\# & 1566 & $73.84 \pm 7.02$ & 0.06 & $-0.4 \pm 0.9$ & 0.32 \\
Insects\# & 1488 & $70.2 \pm 6.52$ & 0.08 & $-0.4 \pm 0.7$ & 0.28 \\
Lepidoptera & 619 & $28.05 \pm 4.6$ & 0.13 & $0.4 \pm 0.5$ & 0.16 \\
Diptera & 138 & $6.41 \pm 2.8$ & 0 & $0.1 \pm 0.9$ & 0.83 \\
Hymenoptera & 263 & $12.58 \pm 3.74$ & 0.09 & $-0.3 \pm 0.6$ & 0.25 \\
Coleoptera & 368 & $18.73 \pm 4.6$ & 0.44 & $-0.8 \pm 0.5$ & $0.004^{*}$ \\
Scolytidae & 69 & $4.0 \pm 2.6$ & 0.36 & $-0.8 \pm 0.6$ & 0.01 \\
Ips & 67 & $3.37 \pm 1.7$ & 0.05 & $-0.2 \pm 0.5$ & 0.38 \\
Dendroctonus & 61 & $3.46 \pm 2.77$ & 0.37 & $-0.9 \pm 0.6$ & $0.009^{*}$ \\
& & & & & \\
\hline
\end{tabular}

${ }^{a} P$ values with asterisks indicate slopes are significantly different from zero $(\alpha=0.05)$. Number (\#) indicates supertaxa designations of BIOSIS (ST codes).

fields were well established as central to chemical ecology by 1975 . In fact, "behavior" is by far the most commonly mentioned field ( $22.9 \%$ of the papers) with "physiology" and "ecology" next at only 3.6\% (Table 5). There is a positive trend in the use of "evolution" and "physiology," while "genetic" increases but is not quite significant.

Electrophysiological studies account for the majority of the physiology papers since $61 \%$ of these had "antennogra" or "electro" (AND + OR search). The word "receptor" also increases in frequency during the period due to the increase in electrophysiological studies. Uses of "herbivore" and "defense" also show increasing trends. The regression line for the percentage of studies mentioning "synergism," "synergist," or "synergistic" (only 3.6\% average) does increase but the slope was not statistically significant from zero (Table 5). It is surprising that synergism is mentioned so sparingly, since it is well estab- 


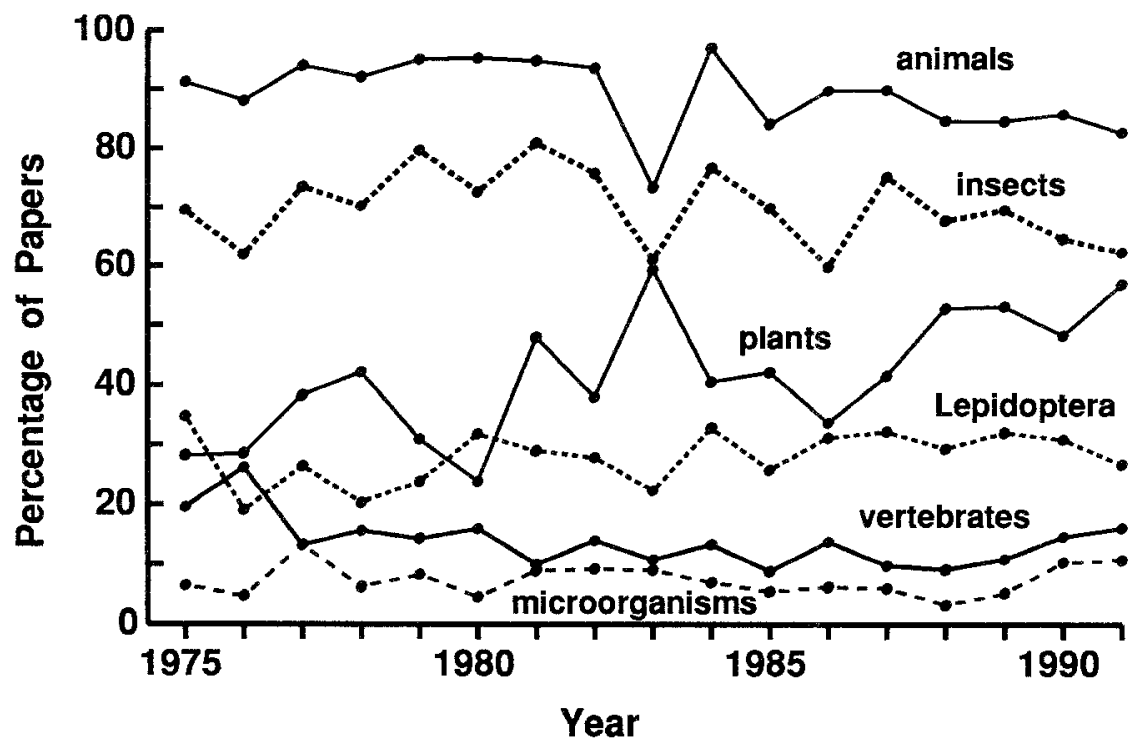

FIG. 4. Percentage of annual papers published in the Journal of Chemical Ecology that concern various supertaxa (as classified by BIOSIS Previews) from 1975 to October 1991.

lished that most pheromones, and probably most semiochemicals, are blends of several synergistic components (Silverstein, 1981; Byers, 1992a).

Deitz and Osegueda (1989) discuss the effectiveness of retrieving entomological literature from several data bases including AGRICOLA, AGRIS International, BIOSIS Previews, CAB Abstracts, Dissertation Abstracts Online, Life Sciences Collection (Cambridge Scientific Abstracts), SCISEARCH, and Zoological Record Online. They show that pertinent literature for a particular subject is likely to be found in any of these data bases in varying proportions and redundancy. While the cost effectiveness may vary depending on the blend of data bases used, it was apparent that BIOSIS Previews had the most relevant references. I have searched CA Search and BIOSIS Previews for all references in the Journal of Chemical Ecology and found that the former contained only about $86 \%$ of the articles while BIOSIS had all of them. Several key word searches and reference retrieval strategies have been proposed (Marshall, 1979; Harvey, 1979; Chiang and Chiang, 1984; Eyers and Taylor, 1988; Resh, 1988; Deitz and Osegueda, 1989). The results of these articles indicate that an exhaustive search of the literature is more costly and difficult than one might anticipate due to the scattering of references and the complexity of designing a key word search profile.

The advantage of building one or more personal data bases from a com- 
Table 3. Positive and Negative Trends from 1975 to 1991 in Percentage of PAPERS IN Joumal of Chemical Ecology InVEstigating Various Methods Found in Title, Key Words, or Abstract (Linear Regression with Arcsin Square Root Transformation of Percentages) ${ }^{a}$

\begin{tabular}{|c|c|c|c|c|c|}
\hline Method & $N$ & Mean $\% \pm \mathrm{SD}$ & $r^{2}$ & Slope $\pm 95 \% \mathrm{CL}$ & $P($ slope $=0)$ \\
\hline Wind tunnel & 37 & $1.56 \pm 1.79$ & 0.43 & $1.0 \pm 0.7$ & $0.004 *$ \\
\hline Bioassay & 332 & $15.37 \pm 3.27$ & 0 & $0.05 \pm 0.5$ & 0.83 \\
\hline Olfactometer ${ }^{a}$ & 50 & $2.15 \pm 1.49$ & 0.26 & $0.6 \pm 0.6$ & 0.04 \\
\hline Fraction & 138 & $6.54 \pm 1.87$ & 0 & $0.04 \pm 0.4$ & 0.83 \\
\hline $\begin{array}{l}\text { Antennogram }{ }^{b} \text { or } \\
\text { electrophysiology }\end{array}$ & 145 & $6.16 \pm 2.79$ & 0.45 & $1.1 \pm 0.6$ & $0.003^{*}$ \\
\hline Method/technique & 157 & $7.66 \pm 3.06$ & 0.02 & $-0.2 \pm 0.6$ & 0.58 \\
\hline Gas chromatography ${ }^{c}$ & 306 & $13.91 \pm 3.63$ & 0.10 & $0.3 \pm 0.6$ & 0.24 \\
\hline Capillary $\mathrm{GC}^{\mathrm{C}}$ & 62 & $2.78 \pm 1.52$ & 0.08 & $0.3 \pm 0.6$ & 0.29 \\
\hline Mass spectrometry ${ }^{b, c}$ & 205 & $9.21 \pm 2.36$ & 0.24 & $0.4 \pm 0.4$ & $0.04 *$ \\
\hline HPLC ${ }^{c}$ & 44 & $1.90 \pm 1.79$ & 0.21 & $0.7 \pm 0.7$ & 0.06 \\
\hline $\mathrm{TLC}^{c}$ & 60 & $2.81 \pm 1.30$ & 0 & $0.05 \pm 0.6$ & 0.87 \\
\hline $\mathrm{NMR}^{r}$ & 35 & $1.52 \pm 1.05$ & 0.05 & $0.3 \pm 0.6$ & 0.37 \\
\hline
\end{tabular}

${ }^{a} P$ values with asterisks indicate slopes are significantly different from zero $(\alpha=0.05)$.

${ }^{b} \mathrm{~A}$ truncation of the word was used, e.g. antennogra(m, phy), to include several possible related words.

${ }^{c}$ Several related words were searched using a multiple $O R$ search, e.g., gas chromatograph, gasliquid chromatograph, gas liquid chromatograph, GC-MS, GLC, or GCMS.

mercial data base such as BIOSIS is that the references in the personal data bases can be searched in many different ways over the course of one's career. This may be much less costly and more convenient than to search the commercial data bases multiple times. The drawback is that some references will be missed but this problem minimizes as the personal data base is enlarged. The located references in the data base usually will contain most of the other references in their "literature cited" sections. Of course, articles dated before 1969-1970 can only be found by searches of these sections.

BIOSIS (2100 Arch St., Philadelphia, Pennsylvania 19103-1399) has informed me that they would like presented the "fair use and copyright" issue concerning the use of their data bases. Their policy on downloaded information is that it "may be freely used without further payment to BIOSIS when temporarily stored in lieu of hard copy or printout form which is the normal medium delivered by a VENDOR." However, the temporary storage/use ceases when USER alters the archival characteristic and incorporates BIOSIS information into an "active" system of any type. Currently, a payment of 15 cents per reference per year is due BIOSIS when one has more than 500 references in an active system. 
Table 4. Positive and Negative Trends from 1975 to 1991 in Percentage of Papers in Journal of Chemical Ecology Mentioning Various Types of Chemicals Found in Title, Key Words, or Abstract (Linear Regression with Arcsin Square Root Transformation of Percentages) ${ }^{a}$

\begin{tabular}{|c|c|c|c|c|c|}
\hline Chemical type & $N$ & Mean $\% \pm \mathrm{SD}$ & $r^{2}$ & Slope $\pm 95 \% \mathrm{CL}$ & $P($ slope $=0)$ \\
\hline Terpene & 144 & $6.17 \pm 2.40$ & 0.08 & $0.3 \pm 0.5$ & 0.28 \\
\hline Acetate & 313 & $15.25 \pm 3.90$ & 0.14 & $-0.4 \pm 0.5$ & 0.14 \\
\hline Hydrocarbon & 102 & $4.76 \pm 2.45$ & 0 & $0.03 \pm 0.8$ & 0.94 \\
\hline Alcohol & 146 & $7.17 \pm 1.88$ & 0.06 & $-0.2 \pm 0.4$ & 0.33 \\
\hline Aldehyde & 132 & $6.43 \pm 2.24$ & 0.01 & $-0.1 \pm 0.5$ & 0.71 \\
\hline Ester & 114 & $5.41 \pm 1.57$ & 0.01 & $-0.1 \pm 0.4$ & 0.65 \\
\hline Ketone & 55 & $2.16 \pm 2.18$ & 0.33 & $1.0 \pm 0.8$ & $0.02 *$ \\
\hline Lactone & 43 & $2.37 \pm 1.66$ & 0.36 & $-0.6 \pm 0.4$ & $0.01 *$ \\
\hline Tetradec & 160 & $7.85 \pm 3.36$ & 0.14 & $-0.5 \pm 0.6$ & 0.13 \\
\hline Phenol & 144 & $6.62 \pm 3.81$ & 0.22 & $0.7 \pm 0.7$ & 0.06 \\
\hline Any above or ${ }^{b}$ & 996 & $47.00 \pm 4.24$ & 0 & $-0.02 \pm 0.5$ & 0.94 \\
\hline Isomer & 141 & $7.39 \pm 2.66$ & 0.49 & $-0.7 \pm 0.4$ & $0.002 *$ \\
\hline Enantiomer ${ }^{c}$ & 70 & $3.23 \pm 1.71$ & 0.05 & $0.3 \pm 0.6$ & 0.37 \\
\hline
\end{tabular}

${ }^{a} P$ values with asterisks indicate slopes are significantly different from zero $(\alpha=0.05)$. ${ }^{b}$ epoxy, tannin, glycoside, quinone, furan, flavone or carbox.

'Or optical isomer.

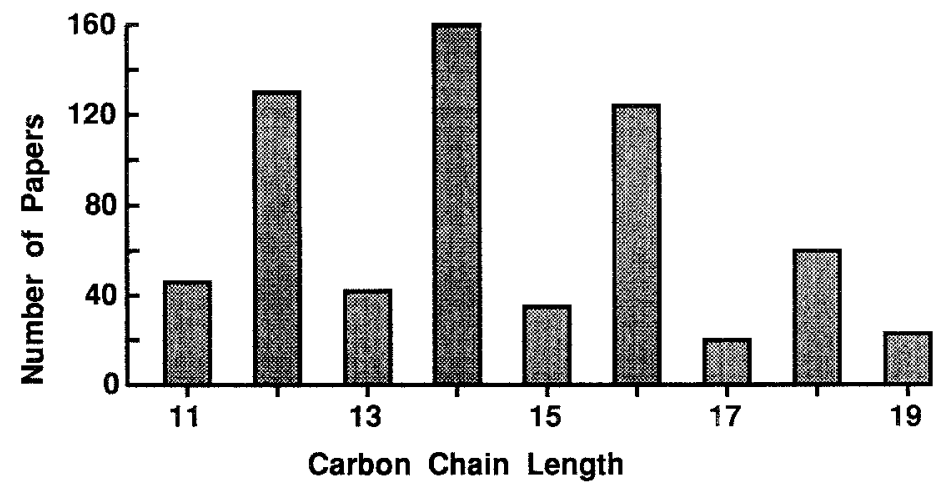

FIG. 5. Number of papers published in the Journal of Chemical Ecology concerning carbon chain lengths of 11 to 19 (1975 to October 1991).

The JCE-REFS.EXE program system can be obtained from the author (send a formatted disk and mailer). Donations of $\$ 5$ or 35 Swedish kronor for shipping would be appreciated. The system can be used to condition BIOSIS Previews files prior to importing them into the scientific reference manager CARD- 
Table 5. Positive and Negative Trends from 1975 to 1991 in Percentage of PAPERs In Journal of Chemical Ecology (1975-1991) USING VARIOUS CHEMICAL

Ecology Terms in Title, Key Words, or Abstract (Linear Regression with arcsin Souare Root Transformation of Percentages) ${ }^{a}$

\begin{tabular}{|c|c|c|c|c|c|}
\hline Term & $N$ & Mean $\% \pm \mathrm{SD}$ & $r^{2}$ & Slope $\pm 95 \% \mathrm{CL}$ & $P($ slope $=0)$ \\
\hline Ecology ${ }^{h}$ & 87 & $3.60 \pm 2.54$ & 0.12 & $0.6 \pm 0.9$ & 0.18 \\
\hline Evolution & 55 & $2.26 \pm 1.64$ & 0.33 & $0.8 \pm 0.7$ & $0.02 *$ \\
\hline Genetic & 37 & $1.55 \pm 1.24$ & 0.22 & $0.6 \pm 0.6$ & 0.005 \\
\hline Behavior & 498 & $22.89 \pm 3.74$ & 0.10 & $2.8 \pm 0.5$ & 0.21 \\
\hline (Top three) & 168 & $6.66 \pm 3.76$ & 0.39 & $1.0 \pm 0.7$ & $0.007^{*}$ \\
\hline (Top four) & 636 & $28.47 \pm 6.03$ & 0.32 & $0.7 \pm 0.6$ & $0.02 *$ \\
\hline Physiology & 88 & $3.63 \pm 2.18$ & 0.44 & $1.1 \pm 0.7$ & $0.004 *$ \\
\hline Habitat & 30 & $1.21 \pm 1.31$ & 0.17 & $0.6 \pm 0.8$ & 0.10 \\
\hline Mating & 85 & $4.32 \pm 1.89$ & 0.15 & $-0.3 \pm 0.5$ & 0.13 \\
\hline Olfactory (tion) & 123 & $5.82 \pm 1.73$ & 0 & $0.02 \pm 0.5$ & 0.92 \\
\hline Aftraction & 187 & $8.77 \pm 2.12$ & 0.01 & $-0.1 \pm 0.4$ & 0.68 \\
\hline Orientation & 44 & $2.15 \pm 1.09$ & 0.05 & $0.2 \pm 0.5$ & 0.38 \\
\hline Herbivore & 63 & $2.43 \pm 1.90$ & 0.41 & $1.0 \pm 0.7$ & $0.006^{*}$ \\
\hline Defense & 128 & $5.44 \pm 2.36$ & 0.48 & $0.7 \pm 0.6$ & $0.002 *$ \\
\hline Calling & 42 & $2.20 \pm 1.38$ & 0.29 & $-0.7 \pm 0.6$ & 0.03 \\
\hline Social & 29 & $1.45 \pm 0.83$ & 0.08 & $-0.2 \pm 0.4$ & 0.27 \\
\hline Synergist $(\mathrm{m}, \mathrm{tic})^{b}$ & 82 & $3.61 \pm 1.13$ & 0.19 & $0.3 \pm 0.3$ & 0.08 \\
\hline Receptor & 82 & $3.41 \pm 1.91$ & 0.36 & $0.9 \pm 0.7$ & $0.01^{*}$ \\
\hline Allelopathy ${ }^{b}$ & 134 & $6.15 \pm 4.74$ & 0.05 & $0.4 \pm 0.9$ & 0.41 \\
\hline Competition & 29 & $1.58 \pm 1.51$ & 0.16 & $-0.5 \pm 0.7$ & 0.12 \\
\hline Adaptation & 37 & $1.75 \pm 1.06$ & 0 & $-0.01 \pm 0.5$ & 0.97 \\
\hline
\end{tabular}

${ }^{a} P$ values with asterisks indicate slopes are significantly different from zero $(\alpha=0.05)$.

${ }^{b}$ A truncation of the word was used, e.g. ecology (y, ical), to include several possible related words.

CAT.EXE (Byers, 1991). Another program system, BIOSIS.EXE (Byers, 1992b), also is used to reformat BIOSIS data base files and is compatible with CARDCAT, but it can make reprint request cards. However, the BIOSIS.EXE program cannot handle abstracts while JCE-REFS.EXE can.

Acknowledgments-Funding for the project was obtained in part from the Swedish Forest and Agricultural Research Council (SJFR). I thank my colleagues of the pheromone research group here in Lund for comments on the manuscript.

\section{REFERENCES}

BYERS, J.A. 1991. Cardcat: A scientific reference manager for IBM-compatible personal computers. Am. Entomol. 37:240-242.

BYERS, J.A. 1992a. Optimal fractionation and bioassay plans for isolation of synergistic chemicals: The subtractive-combination method. J. Chem. Ecol. Submitted. 
BYERS, J.A. 1992b. Conversion of BIOSIS Previews database files to reference text files and reprint request forms. Am. Entomol. In press.

Chiang, K.S., and Chiang, H.C. 1984. Literature retrieval in entomology. J. Entomol. Res. 8:8688.

DEITZ, L.L., and OSEGUEDA, L.M. 1989. Effectiveness of bibliographic data bases for retrieving entomological literature: A lesson based on the Membracoidea (Homoptera). Bull. Entomol. Soc. Am. 35:33-39.

EYERS, J.E., and TAYLOR, E.R. 1988. Online searching of parasitology literature. Parasitol. Today $4: 324-328$.

HARVEY, S. 1979. CAB/CAIN evaluation project: A comparative study on the performance of two agricultural databases in a computerized current awareness service. (British Library Research and Development Report 5483). Centre for Agricultural Publishing and Documentation, Wageningen, Netherlands.

MarShall, K.E. 1979. Online retrieval of information: A comparison of different systems used to produce a bibliography on Ephemeroptera and pollution, 1969-78. Canada Fisheries and Marine Services Technical Report 878, Winnipeg, Manitoba.

RESH, V.H. 1988. Publication patterns in entomology: An example based on aquatic insects. Bull. Entomol. Soc. Am. 34:145-150.

Silverstein, R.M. 1981. Pheromones: Background and potential for use in insect pest control. Science 213:1326-1332. 